Musées, Patrimoine et Culture scientifiques et techniques

\title{
Un bénévole pas comme les autres : Rahan, promoteur de la recherche
}

\section{Catherine Ruppli}

\section{(2) OpenEdition \\ Journals}

Édition électronique

URL : http://journals.openedition.org/ocim/397

DOI : 10.4000/ocim.397

ISSN : 2108-646X

Éditeur

OCIM

Édition imprimée

Date de publication : 1 novembre 2010

Pagination : 54-55

ISSN : 0994-1908

Référence électronique

Catherine Ruppli, «Un bénévole pas comme les autres : Rahan, promoteur de la recherche », La Lettre de l'OCIM [En ligne], 132 | 2010, mis en ligne le 01 novembre 2012, consulté le 21 avril 2019. URL : http://journals.openedition.org/ocim/397 ; DOI : 10.4000/ocim.397

Ce document a été généré automatiquement le 21 avril 2019.

Tous droits réservés 


\title{
Un bénévole pas comme les autres: Rahan, promoteur de la recherche
}

\author{
Catherine Ruppli
}

1 L'exposition Rahan à Romain-la-Roche, dont le point de départ est la parution d'une nouvelle aventure de «l'homme des âges farouches ", précisément à Romain-la-Roche, site paléontologique du Pays de Montbéliard (- 160000 ans environ), s'attaque à un défi ambitieux : allier 3 productions différentes pour, en les imbriquant, proposer au visiteur une unité de parcours et de sens. Tout d'abord, le musée de Montbéliard accueille l'exposition itinérante Rahan produite il y a quelques années par le musée des Tumulus de Bougon, centrée sur la bande dessinée et le héros qu'elle fait vivre, au gré parfois d'une grande liberté scientifique. L'exposition comprend également le matériel paléontologique mis à jour depuis 30 ans par Archéofaune Comtoise, une association de bénévoles qui défend le patrimoine de Romain-la-Roche. Enfin, des reconstitutions d'animaux préhistoriques grandeur nature complètent les présentations (panneaux de textes, planches de BD, objets, maquettes).

2 Beaucoup reste à dire sur l'exposition, son sujet, sa scénographie... mais si l'on devait résumer en trois mots l'exposition orchestrée par le muséum Cuvier (composante Histoire naturelle qui, avec l'Archéologie et l'Art contemporain, constitue le musée du Château des Ducs de Wurtemberg), ce serait à n'en pas douter : recherche, bénévolat et collaboration.

3 Comme l'a rappelé Thierry Malvesy, responsable du muséum Cuvier, lors de l'inauguration de Rahan à Romain-la-Roche, le musée a un rôle de facilitateur de la recherche avec bien sûr, la conservation des collections, mais également leur mise à disposition auprès des chercheurs pour favoriser leur étude. C'est ainsi que les collections issues du site de Romain-la-Roche feront, dans les prochains mois, l'objet de publications scientifiques dont leurs auteurs ont bien voulu proposer un aperçu dans les textes qui accompagnent les objets présentés dans l'exposition.

4 Ces collections, au centre de l'exposition, sont le fruit du travail acharné et de l'engagement sans faille de bénévoles, regroupés au sein de l'association Archéofaune 
Comtoise, qui a géré les 25000 ossements et fragments d'ossements découverts jusqu'à leur dépôt au muséum Cuvier en 2002. Cette dynamique de bénévolat a su alerter les différentes strates publiques et obtenir progressivement un soutien des différents acteurs impliqués, dont le muséum Cuvier depuis de longue date.

Cette complémentarité entre le soutien public et l'engagement individuel, très visible le jour de l'inauguration de l'exposition, constitue aujourd'hui encore plus qu'hier un terreau collaboratif auquel le muséum Cuvier contribue tout en en recevant les bénéfices : collaboration bien sûr avec les autres secteurs du musée du Château, avec les différents services de la Ville (comme en témoigne la signalétique extérieure, développée par les Espaces verts, qui accompagne chaque exposition temporaire), plus largement avec les acteurs scientifiques notamment universitaires, les associations de protection de l'environnement ou de valorisation d'un territoire...

$6 \mathrm{Si}$, comme toutes les expositions temporaires, Rahan à Romain-la-Roche s'inscrit dans une logique événementielle, elle permet de mettre en lumière le travail de fond et de longue haleine mené par le muséum Cuvier pour favoriser et soutenir le maillage scientifique et culturel du Pays de Montbéliard.

\section{RÉSUMÉS}

Depuis le 15 octobre 2010 et jusqu'au 27 février 2011, Rahan, personnage mythique pour les lecteurs de Pif Gadget dans les années 1970, occupe le musée du Château des Ducs de Wurtemberg à Montbéliard (25).

\section{INDEX}

Mots-clés : collections, exposition, paléontologie, visite

Index géographique : France, Montbéliard

\section{AUTEUR}

\section{CATHERINE RUPPLI}

Adjointe à la Direction, OcIM. catherine.ruppli@u-bourgogne.fr 